\section{LEFT VENTRICULAR RCONSTRUCTION SURGERY}

Steven SL Tsui. Department of Cardiothoracic Surgery, Royal Papworth Hospital, Cambridge, UK

10.1136/heartasia-2019-apahff.17

Acute myocardial infarction and ischaemic cardiomyopathy are important causes of heart failure (HF). With ageing populations in developed nations, the incidences can be expected to rise in the coming decades.

Stretch of a left ventricle (LV) scar results in detrimental ventricular remodelling, LV dilatation and a change in geometry from elliptical to spherical. These result in higher wall stress and less effective ventricular contractions.

Surgical techniques to restore the shape of the remodelled ventricle were introduced in early 1980s. ${ }^{1}$ The RESTORE registry and others reported favourable outcomes in >5000 patients. $^{2}$ However, the NHLBI and NIH-funded prospective randomised STICH Trial found no additional benefit of $\mathrm{LV}$ reconstruction in addition to coronary bypass grafting. ${ }^{3}$

The STICH Trial was well conducted. The neutral findings did curb enthusiasm for LV reconstruction surgery. However, the interpretation of STICH was not incontrovertible and had sparked heated debates. ${ }^{4}$ Subsequent re-analysis of STICH confirmed significant survival benefit when adequate LV volume reduction was achieved. ${ }^{5}$

New data from experienced centres continued to demonstrate efficacy of LV reconstruction surgery. ${ }^{6}{ }^{7}$ The 2013 ACCF/AHA Guideline for the Management of Heart Failure recommended LV reconstruction for HF with reduce ejection fraction with a recommendation class IIb, level of evidence B. ${ }^{8}$ Unsurprisingly, the field remains confused about the role of this treatment.

In order to facilitate appropriate sizing of the LV during reconstruction, graduated balloons are now available for use as templates. A new device has been developed for less invasive off-pump LV reconstruction and a Phase 2 clinical trial is now underway.

\section{REFERENCES}

1. Dor V. Reconstructive left ventricular surgery for post-ischemic akinetic dilatation. Semin Thorac Cardiovasc Surg 1997;9:139-145.

2. Athanasuleas $C L$, Buckberg GD, Stanley AW, Siler W, Dor V, Di Donato M, Menicanti L, Almeida de Oliveira S, Beyersdorf F, Kron IL, Suma H, Kouchoukos NT, Moore W, McCarthy PM, Oz MC, Fontan F, Scott ML, Accola KA; RESTORE group. Surgical ventricular restoration in the treatment of congestive heart failure due to post-infarction ventricular dilation. I Am Coll Cardiol 2004; $44: 1439-1445$

3. Jones RH, Velazquez EJ, Michler RE, Sopko G, Oh JK, O'Connor CM, Hill JA, Menicanti L, Sadowski Z, Desvigne-Nickens P, Rouleau JL, Lee KL; STICH Hypothesis 2 Investigators. Coronary bypass surgery with or without surgical ventricular reconstruction. N Engl J Med 2009;360:1705-1717.

4. Buckberg GD, Athanasuleas CL. The STICH trial: misguided conclusions. J Thorac Cardiovasc Surg 2009:138:1060-1064.

5. Michler RE, Rouleau JL, Al-Khalidi HR, Bonow RO, Pellikka PA, Pohost GM, Holly TA, Oh JK, Dagenais F, Milano C, Wrobel K, Pirk J, Ali IS, Jones RH, Velazquez EJ, Lee KL, Di Donato M; STICH Trial Investigators. Insights from the STICH trial: change in left ventricular size after coronary artery bypass grafting with and without surgical ventricular reconstruction. J Thorac Cardiovasc Surg 2013;146:11391145.

6. Dor V, Civaia F, Alexandrescu C, Sabatier M, Montiglio F. Favorable effects of left ventricular reconstruction in patients excluded from the Surgical Treatments for Ischemic Heart Failure (STICH) trial. J Thorac Cardiovasc Surg 2011;141:905-916.

7. Calafiore AM, laco' $A L$, Kheirallah $H$, Sheikh AA, Al Sayed $H$, El Rasheed M, Allam A, Awadi MO, Alfonso JJ, Osman AA, Di Mauro M. Outcome of left ventricular surgical remodelling after the STICH trial. Eur J Cardiothorac Surg 2016;50:693-701.
8. Yancy CW, Jessup M, Bozkurt B, Butler J, Casey DE Jr, Drazner MH, Fonarow GC, Geraci SA, Horwich T, Januzzi JL, Johnson MR, Kasper EK, Levy WC, Masoudi FA, McBride PE, McMurray JJ, Mitchell JE, Peterson PN, Riegel B, Sam F, Stevenson LW, Tang WH, Tsai EJ, Wilkoff BL; American College of Cardiology Foundation; American Heart Association Task Force on Practice Guidelines. 2013 ACCF/AHA guideline for the management of heart failure: a report of the American College of Cardiology Foundation/American Heart Association Task Force on Practice Guidelines. J Am Coll Cardiol 2013;62:e147-239.

\section{SURGERY FOR HEART FAILURE: EXPERIENCES FROM SEVERANCE CARDIOVASCULAR HOSPITAL, SEOUL, KOREA}

Jung-Hwan Kim. Division of Cardiovascular Surgery, Department of Thoracic and Cardiovascular Surgery, Severance Cardiovascular Hospital, Yonsei University College of Medicine, Seoul, Korea

\subsection{6/heartasia-2019-apahff.18}

Since the first successful heart transplant in Korea in 1992, the case volume has been rapidly increasing. Compared with ISHLT registry data, the Korean KONOS registry data show similar post-transplant long-term survival rates. At Severance Cardiovascular Hospital (SCH) of Yonsei University, the number of heart transplants has been growing steadily since 2010. Between 1994 and 2018, 174 heart transplantations had been performed. Mean age of recipients and their follow-up duration were 42.9 and 3.2 years, respectively. Preoperative CPR was performed in 18 (10.3\%) patients, and extracorporeal membrane oxygenation (ECMO) was applied in $35(20.1 \%)$ patients. In-hospital mortality was 19\% and 10 year survival rate was $71.7 \%$. By multivariate analysis, risk factors for in-hospital mortality were pre-operative elevated bilirubin and lactate levels. Risk factors for overall mortality were pre-operative dialysis, and high bilirubin and lactate levels. Gender and pre-operative body weight mismatch and ECMO bridging were not independent risk factors for mortality.

The volume of LVAD implants had been low in Korea due to reimbursement limitations. However, from October 2018, a new national insurance policy was implemented to provide for 95\% of total device cost. This change is projected to increase device implant rates and patient access.

In conclusion, size-mismatch did not affect LVAD outcomes for the East Asian population. Organ protection remains an important factor for long-term survival. In the short term, MCS including ECMO may be used to reverse organ dysfunction as a bridge to recovery or decision. Finally, LVAD will be a main strategy for bridge-to-transplant (BTT) in Korea.

\section{UPDATE OF LVAD THERAPY IN JAPAN}

Goro Matsumiya. Department of Cardiovascular Surgery, Chiba University Graduate School of Medicine, Chiba, Japan

\subsection{6/heartasia-2019-apahff.19}

Left ventricular assist device (LVAD) has been increasingly utilised for the treatment of advanced (ACC/AHA stage D) heart failure. Three types of implantable device (HeartMate $\mathrm{II}^{\mathrm{TM}}$, Jarvik $2000^{\circledR}$, and EVAHEART ${ }^{\mathrm{TM}}$ ) are currently available as a bridge-to-transplant in Japan. 
J-MACS (Japanese registry for mechanically assisted circulatory support) has listed a total of 722 patients between December 2010 and October 2017. Mean age was 43.2 years and mean body surface area was $1.63 \mathrm{~m}^{2}$. Aetiology of heart failure was dilated cardiomyopathy in $77 \%$ and ischaemic cardiomyopathy in 11\%. Pre-operative INTERMACS profile was level 1 in 10\%, level 2 in 39\%, level 3 in 48\%, and level 4 or 5 in $4 \%$. One hundred forty-nine (21\%) patients received extracorporeal life support device first for cardiogenic shock or bridge-to-candidacy, and then underwent switch to implantable devices (bridge-to-bridge). Overall survival rate after LVAD implantation was $90 \%$ at 1 year and $86 \%$ at 2 years. Competing outcome analyses demonstrated that only $10 \%$ of patients reached heart transplantation and 60\% were still on device therapy at 3 years. Causes of death were cerebrovascular accident in 44\%, infection in $18 \%$, bleeding in $6 \%$, and device failure in $6 \%$. Sixty-six per cent of patients required at least 1 hospital admission during an initial 1 year after device implantation.

In conclusion, continuous flow LVAD was effective for bridge-to-transplant. Although the collected data indicate that the improved survival rate is acceptable, there remains potential for major complications which precludes wider application of LVAD.

\section{DEVELOPING COMPREHENSIVE MECHANICAL CIRCULATORY SUPPORT IN SINGAPORE}

Cumaraswamy Sivathasan. Mechanical Circulatory Support and Transplantation, National Heart Centre Singapore, Singapore

10.1136/heartasia-2019-apahff.20

Heart transplantation was initiated in Singapore in 1990. Three to six heart transplants are performed annually. The waiting list mortality was about $30 \%$. Hence, mechanical circulatory support was initiated with HeartMate I in 2001. Extracorporeal membrane oxygenation (ECMO) for acute life support became available by 2003. Durable implantable rotary left ventricular assist device (LVAD) with HeartMate II $^{\mathrm{TM}}$ (HMII) was introduced in 2007, followed by HeartWare ${ }^{\mathrm{TM}}$ $\mathrm{HVAD}^{\mathrm{TM}}$ in 2012 and HeartMate $3^{\mathrm{TM}}$ (HM3) in 2015.

90 consecutive durable implantable devices (58 HMII, 21 HVAD and 11 HM3), were placed from May 2009 to December 2017. Of these, 65 were placed as bridge-to-transplant. Overall perioperative mortality was 7 (7.7\%). 26 were INTERMACS level 1 patients, bridged with ECMO without perioperative mortality. Median ICU stay and hospital stay were 8 and 31 days, respectively. Mean duration of support was 907 days. The longest support was 8.6 years. 45 had been on ongoing support, and 23 were transplanted. Late mortality occurred in 13 patients, 5 due to stroke. Driveline infection developed in 28.7\%. 57.1\% were associated with driveline trauma. Pocket infection developed in 5 patients. In the initial 78 patients, $17(21.7 \%)$ experienced gastrointestinal bleeding (GIB); 11 with recurrent GIB were successfully treated with thalidomide. 6 developed aortic regurgitation, 5 underwent modified Park stitch. Implantable cardioverter defibrillator placement pre-LVAD did not confer mortality benefit. Issues with hardware occurred in 60\%. Cardiac recovery occurred in 2 and their LVADs were decommissioned. Overall survival at 5 years was $84.4 \%$, compared with INTERMACS registry data of $48 \%$.

\section{SURGICAL CARE AND PERIOPERATIVE NURSING MANAGEMENT OF LVADS}

Jesus M Casida. Johns Hopkins School of Nursing, Baltimore, Maryland, USA

10.1136/heartasia-2019-apahff.21

The perioperative management of patients with a left ventricular assist device (LVAD) presents a whole set of challenges to the nurses at the bedside and outpatient settings. ${ }^{1}$ Despite the remarkable advancements in technology, the care of patients following LVAD implant remains complex for the multidisciplinary healthcare team. This presentation provides a brief overview of the currently used durable LVAD designs worldwide. These include axial (HeartMate $\mathrm{II}^{\mathrm{TM}}$ ) and magnetic flow levitation (HeartMate $3^{\mathrm{TM}}$ and HeartWare HVAD $^{\circledR}$ ) LVADs. $^{2}$ Discussion of the nursing management of patients post-LVAD implant in the critical care, progressive care, and in the outpatient care settings will be approached at conceptual level. This approach will equip the participant with a 'thinking framework' guiding his/her actions in caring for LVAD patients. Salient nursing actions include early detection and management of post-surgical complications, device-related complications, heart failure symptom exacerbations, infection, among others. The nurse's role in helping patients attain an optimum level of functioning post-implantation during hospitalisation and the impact of the nurse in supporting patients (and caregivers) to attain an increase in quality of life are highlighted.

\section{REFERENCES}

1. Chmielinski $A$, Koons $B$. Nursing care for the patient with a left ventricular assist device. Nursing 2018. 2017:47:34-40.

2. Montalto A, Loforte A, Musumeci F, Krabatsch T, Slaughter M (Eds.). Mechanical circulatory support in end-stage heart failure: a practical manual. Cham, Switzerland: Springer International Publishing; 2017. doi:10.1007/978-3-31943383-7

\section{RENAL COMPLICATIONS IN LVAD AND HEART TRANSPLANT PATIENTS}

Michael S Kiernan. CardiVascular Center, Tufts Medical Center and Tufts University School of Medicine, Boston, Massachusetts, USA

10.1136/heartasia-2019-apahff.22

Renal dysfunction remains a primary determinant of both short- and long-term outcomes following heart transplantation (HTx) and ventricular assist device (VAD) implantation. ${ }^{1}{ }^{2}$ Challenging to the assessment of candidacy for advanced heart failure (HF) therapies is the ability to distinguish intrinsic parenchymal renal disease from reversible cardiorenal disease. Patients with haemodynamically mediated renal failure may recover kidney function once renal perfusion is restored following HTx or VAD surgery. Chronic hypoperfusion, however, can lead to progressive structural lesions that may not improve despite correction of underlying haemodynamic abnormalities. In patients undergoing kidney biopsy as part of their HTx evaluation, there was poor correlation between eGFR and the extent of tubular atrophy and interstitial fibrosis. ${ }^{3}$ Prolonged elevation of serum creatinine (SCr) levels suggest but do not prove irreversibility and $\mathrm{SCr}$ in isolation is unlikely the best biomarker to determine transplant candidacy in this clinical setting. Reasons for SCr elevation in $\mathrm{HF}$ including pharmacotherapies such as renin-angiotensin- 